\title{
Serine-threonine kinases and transcription factors active in signal transduction are detected at high levels of phosphorylation during mitosis in preimplantation embryos and trophoblast stem cells
}

Jian Liu ${ }^{1}$, Elizabeth E Puscheck ${ }^{1}$, Fangfei Wang ${ }^{1}$, Anna Trostinskaia $^{1}$, Dusan Barisic ${ }^{1}$, Gordon Maniere ${ }^{1}$, Dana Wygle ${ }^{1}$, W Zhong ${ }^{2}$, Edmond H H M Rings ${ }^{5}$ and Daniel A Rappolee ${ }^{1,2-4}$

${ }^{1}$ C S Mott Center for Human Growth and Development, Department of Obstetrics and Gynecology, Hutzel Hospital, Wayne State University School of Medicine, ${ }^{2}$ Department of Anatomy and Cell Biology, Wayne State University School of Medicine, ${ }^{3}$ Karmanos Cancer Institute, Wayne State University School of Medicine and ${ }^{4}$ Insitute for Environmental Health Science, Wayne State University School of Medicine, Detroit, Michigan 48201, USA and ${ }^{5}$ Department of Pediatrics, Center for Liver, Digestive and Metabolic Diseases, Academic Hospital Groningen, Groningen, The Netherlands

Correspondence should be addressed to Daniel A Rappolee, C S Mott Center for Human Growth and Development, Wayne State University School of Medicine, 275 East Hancock, Detroit, Michigan 48201, USA; Email:

drappole@med.wayne.edu

\begin{abstract}
Serine-threonine kinases and transcription factors play important roles in the G1-S phase progression of the cell cycle. Assays that use quantitative fluorescence by immunocytochemical means, or that measure band strength during Western blot analysis, may have confused interpretations if the intention is to measure G1-S phase commitment of a small subpopulation of phosphorylated proteins, when a larger conversion of the same population of proteins can occur during late G2 and M phases. In mouse trophoblast stem cells (TSC), a human placental cell line (HTR), and/or mouse preimplantation embryos, 8/19 serine-threonine and tyrosine kinases, 3/8 transcription factors, and 8/14 phospho substrate and miscellaneous proteins were phosphorylated at higher levels in $M$ phase than in interphase. Most phosphoproteins appeared to associate with the spindle complex during $M$ phase, but one (p38MAPK) associated with the spindle pole and five (Cdx2, MEK1, 2, p27, and RSK1) associated with the DNA. Phosphorylation was detected throughout apparent metaphase, anaphase and telophase for some proteins, or for only one of these segments for others. The phosphorylation was from 2.1- to 6.2-fold higher during $\mathrm{M}$ phase compared with interphase. These data suggest that, when planning and interpreting quantitative data and perturbation experiments, consideration must be given to the role of serine-threonine kinases and transcription factors during decision making in $\mathrm{M}$ phase as well as in G1-S phase.

Reproduction (2004) 128 643-654
\end{abstract}

\section{Introduction}

About $70 \%$ of fertilized human embryos are lost before birth and the majority of these are lost at the time of implantation in the uterus (Cross et al. 1994, Rappolee 1999). Since insufficient trophoblast proliferation is one of the causes for loss of embryos, studies on trophoblast proliferation will improve our understanding of the mechanisms underlying trophoblast growth and will help prevent loss of embryos. Cell cycle progression is an important part of cell proliferation. Serine-threonine kinases and transcription factors play important roles in the progression of the cell cycle (Roovers \& Assoian 2000, Wilkinson \& Millar 2000, Rappolee 2003).

Many investigations on the roles of serine-threonine kinases and transcription factors in mitosis have been carried out in mammalian somatic cells, but little has been done in preimplantation embryos. G1-S phase mitogenic signal transduction is largely mediated by protein kinases; examples include the Raf family, the mitogen activated protein kinase (MAPK) family, the MAPK activating kinase (MEK) family (Roovers \& Assoian 2000, Wilkinson \& Millar 2000) and transcription factors (e.g. MycC, fos; Sears \& 
Nevins 2002). These transcription factors are downstream of receptor tyrosine kinases (RTK) such as the fibroblast growth factor (FGF) receptor family that mediate a necessary mitogenic input into placental trophoblasts in the preimplantation mouse embryo (Chai et al. 1998). During this important period of decision-making, only small subpopulations of protein kinases may be phosphorylated and perform downstream functions. However, elevated (putatively quantitative) conversion of populations of protein kinases and transcription factors has been observed during late G2, and throughout $\mathrm{M}$ phase in somatic cells (Willard \& Crouch 2001). Western blotting was used to determine that some serine-threonine kinases were hyper-phosphorylated at $\mathrm{M}$ phase in the first two cell divisions of the mouse embryo, but later preimplantation cell divisions showed no hyper-phosphorylation (Iwamori et al. 2000).

The unique role of kinases during $\mathrm{M}$ phase is intriguing, but not totally understood. It is likely that (1) there is a change in the substrate range of kinases during $M$ phase, (2) the change must happen quickly due to the short duration of mitosis, and (3) a great number of $M$ phase structural molecules (such as cytoskeletal tubulin) must be phosphorylated. It is likely that nearly $100 \%$ of kinases of one type may be converted for about $1 \mathrm{~h}$ of mitosis, but less than $10 \%$ are converted for a few hours of G1 preceding S phase (Whitmarsh \& Davis 1999, 2000, Willard \& Crouch 2001). It is therefore important to know about the kinases and transcription factors that are used by the preimplantation embryo for $M$ phase, if correct interpretations about function at the G1-S phase are to be made.

The purpose of this study was to investigate the expression of activated phosphorylated serine-threonine kinases and transcription factors during mitosis in mouse preimplantation embryos and mouse and human trophoblast cells.

\section{Materials and Methods \\ Reagents}

The antibodies used were: 14-3-3 phospho substrate (CS9601), Akt phospho SER473 (CS9271), Akt all forms (SC5298), Akt1 phospho substrate (CS9611), ATF2 phospho THR71 (CS9221), ATF2 all forms (CS9222), ATM phospho ser1981 (CS4526), ATM/ATR phospho substrate (CS2851), CDK2-phospho THR160 (CS2561), Elk-1 phospho SER383 (CS9186), Elk-1 all forms (SC355, CS9182), Ets2 (SC351), FGFR1 phospho TYR766 (SC12935), FGFR1 all forms (SC121), FRS2alpha phospho (CS3861), FRS2 $\alpha$ all forms (SC7131), GSK3 $\alpha$-phospho SER21/9 (CS9331), Jun-C phospho SER63 (CS9261, SC7980-R), jun-C all forms (CS9262), MAPK/ERK phospho THR202/TYR204 (CS9101), MAPKERK all forms (CS9102), MAPK/ERK phospho THR202/TYR204 (CS9106), MAPK-phospho THR202/ TYR204 (CS9106), MAPK-phospho THR183/TYR185 (M8159, Sigma Chemical Co., St Louis, MO, USA), MAPK phospho (UBI 06-64206, Upstate Biotechnology Inc, Lake
Placid, NY, USA), MAPK5/ERK5 all forms (SC1284, SC1285), ERK5 phospho Thr215 Tyr220 (CS3371), MEK1 all forms (SC219), MEK1 all forms (SC436), MEK1,2 all forms (CS9122), MEK1,2 phospho SER217/SER221 (CS9121), MEK5 all forms (SC10795), MEK5 all forms (SC9320), MSK-1 phospho SER360 (CS9594), MycB phospho SER68 (SC16303R), myc C all forms rabbit (SC788), MycC phospho THR58/SER62 (CS9401, SC8000R), p27 (SC528), p27KIP1 all forms (MS-256-P0, clone 16P07 Ab1), p27 phospho SER10 (SC12939R), p38MAPK all forms (CS9212), p38MAPK phospho THR180/TYR182 (CS9211), p53 phospho SER15 (SC11764-R), p57 (SC8298), p57KIP2 all forms (MS-1062-P0, Ab6, clone 16P07), 3-phosphoinositide-dependent protein kinase (PDK) phospho SER241 (CS3061), PDK phospho substrate (CS2291, protein kinase (PK) A (PKA) phospho substrate (CS9621), PKC phospho substrate (CS2261), Raf1 all forms (SC7198), retinoblastoma (Rb) protein phospho SER795 (CS9301, SC7986R), ribosomal S6 kinase (RSK) 1 phospho THR573 (RSK1) (CS9346), RSK1 all forms (SC231), RSK1 phospho SER380 (CS9341), 90RSK3 all forms (SC1431), 90RSK2 all forms (SC1430), RSK1 all forms (RSK1) (CS9342), RSK1 phospho THR359/SER363 linker (RSK1) (CS9344), RSK2 all forms (SC1430), RSK3 all forms (SC1431), RSK2,1 phospho SER380 (SC11756), RSK3 phospho (CS9345), stress activated protein kinase (SAPK)/JNK all forms (CS9252), SAPK/JNK phospho THR183/TYR185 (CS9251), SOS1 all forms (SC10803, SC256), STAT1 phospho TYR701 (CS9171), THR phospho (SC9381), TYR phospho (PY350)(SC18182). All antibodies designated CS are from Cell Signaling (Beverly, MA, USA), all antibodies designated SC are from Santa Cruz Biotechnology (Santa Cruz, CA, USA) and all antibodies designated MS are from Lab Vision (Fremont, CA, USA).

\section{Collection of mouse embryos}

Standard techniques were used for obtaining mouse embryos (Hogan et al. 2002). Female MF-1 mice (4-5 weeks old, Harlan Sprague Dawley, Indianapolis, IN, USA) were injected intraperitoneally with $10 \mathrm{IU}$ pregnant mares' serum gonadotropin (Sigma Chemical Co.), followed by an injection of $7.5 \mathrm{IU}$ human chorionic gonadotropin (Sigma Chemical Co.) $44-48 \mathrm{~h}$ later. After the second injection, females were housed overnight with $\mathrm{C} 57 \mathrm{BL} / 6 \mathrm{~J} \times \mathrm{SJL} / \mathrm{J}$ F1 hybrid males (Jackson Laboratories, Bar Harbor, ME, USA). Noon of the day following coitus was considered day E0.5. For immunocytochemical (ICC) analysis, embryos were obtained at the morula/early cavitation blastocyst (E3.5), or at the 8-cell/compaction (E2.5) stage; for reverse transcriptase-polymerase chain reaction (RT-PCR), embryos were collected at the following stages: unfertilized egg, 2-cell stage (E1.5), 8-cell/compaction stage (E2.5) and morula-early blastocyst (E3.5) stage. The animal use protocols were approved by the Wayne State University Animal Investigation Committee. 


\section{Placenta cell culture}

Mouse TSC (Tanaka et al. 1998) and SV40 large T transformed human trophoblast cells (HTR) (Graham et al. 1993) were cultured as described. In a few experiments, TSC were cultured overnight with $0.5 \mu \mathrm{g} / \mathrm{ml}$ of a commercial colchicine analog, Karyomax Colcemid (Gibco/BRL Gaithersburg, MD, USA), which blocked most cells in late G2-prophase, not in metaphase.

\section{Indirect immunocytochemistry and nuclear staining}

For immunocytochemical analysis, TSC, HTR and E3.5 mouse embryos were fixed for $30 \mathrm{~min}$ in $2 \%$ fresh paraformaldehyde $(\mathrm{pH}$ 7.4) in phosphate-buffered saline (PBS), quenched with $0.1 \mathrm{M}$ glycine, and permeabilized for $10 \mathrm{~min}$ with $0.25 \%$ Triton X-100. The embryos were stained with primary antibodies (diluted at 1:100 in PBSTween with $10 \%$ fetal calf serum). The primary antibody was followed by staining with biotinylated IgG (Vector Labs, Burlingame, CA, USA). Proteins were visualized with fluorescein isothiocyanate (FITC) coupled to streptavidin (Vector Labs). Nuclear counterstaining was carried out with Hoechst $33258(10 \mu \mathrm{g} / \mathrm{ml})$. Photomicrography was carried out with a Leica DM IRE2 epifluorescence microscope with a Retiga 1350 Ex cooled charge coupled device controlled electronically by SimplePCI Al module software. Nearest or no neighbor deconvolution was performed using the SimplePCI DNN module. Photographs were analyzed using Photodex CPIC and C-Imaging Simple $\mathrm{PCl}$ intensity analysis software (Compix Inc., Imaging Systems, Cranberry Township, PA, USA) and formatted for presentation using Adobe Photoshop 6.0 (San Jose, CA, USA). All fluorescence photos were handled and analyzed in the same way. All experiments were repeated at least twice with similar results.

\section{Statistical analysis}

The data in this study are representative of $2-3$ independent studies and are given as means \pm S.D. Statistical significance of differences between different samples was calculated by Student's $t$-test (SPSS 10.0 and SISA website, Uitenbroek 1997). P-values of less than 0.05 were considered significant.

\section{Results}

We investigated the high levels of phosphorylation of 19 serine-threonine and tyrosine kinases, 8 transcription factors, and 14 other proteins or substrate groups during mitosis (Fig. 1) in embryos, and in TSC and HTR cells. In general, all threonine substrates are elevated at mitosis (Fig. 2; note that figures including all controls for published Figs $2-8$ are provided as supplementary figures to the online version of Reproduction (see http://reproductiononline.org/content/vol128/issue5/index.shtml); supplemental Fig. 6), suggesting that serine-threonine kinase plays a role in the regulation of mitosis. In embryos, TSC and HTR it was found that among the individual serine-threonine and tyrosine kinases studied, the following had a high level of phosphorylation during mitosis: ATM (ataxia telangiectasia mutants, note that 5 additional figures not published are available at an on-line database; supplemental Fig. 1), MEK1, 2 and p27 (Fig. 3, supplemental Fig. 7), RSK1, 3 (Figs 4 and 5, supplemental Figs 8 and 9), and p38MAPK (Fig. 6, supplemental Fig. 10) (Table 1). Among the transcription factors, we found a high mitotic phosphorylation of MycB (supplemental Fig. 2), MycC (Fig. 7, supplemental Fig. 11), and Cdx (Fig. 8, supplemental Fig. 12), in embryos, HTR, and TSC (3/8 phosphoprotein transcription factors studied had elevated $M$ phase fluorescence) (Table 2).

The signaling enzymes and transcription factors studied that are (or are not) highly phosphorylated at the $\mathrm{M}$ phases are listed in Tables 1 and 2. The duration of their elevation during mitosis is shown in Fig. 9. Mitosis typically lasts for approximately one hour in somatic cells, and only a few of the proteins studied had elevated phosphorylation during all of mitosis. The cell cycles in both HTR and TSC cells are close to $24 \mathrm{~h}$ (data not shown) and the preimplantation mouse embryo has a cell cycle at E3.5 of about $12 \mathrm{~h}$ (Pedersen 1987, Hogan et al. 2002). Confidence in our ability to detect low frequency events such as metaphase, or other segments of the $M$ phase, was based on a survey of over 60000 micrographs of embryos and placental cell lines. The morphology of mitotic cells was clear in HTR and TSC. In embryos, it was more difficult to detect classic metaphase plates although they were visible

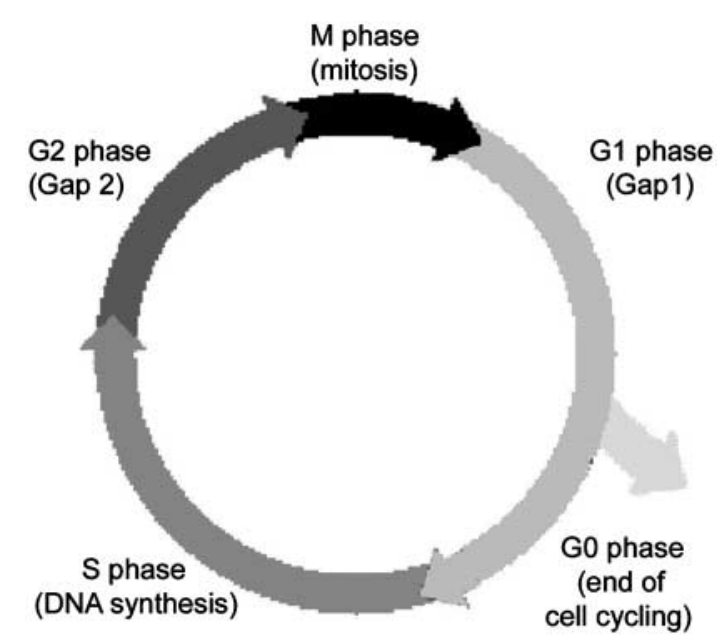

Figure 1 Cell cycle diagram showing the short mitosis phase that averages about $1 \mathrm{~h}$ and the longer $\mathrm{S}$ phase (DNA synthesis) that averages about $8 \mathrm{~h}$ in somatic cells. Other cell cycle phases include G1 (Gap1) when the decision to commit to $S$ phase is made, G2 (Gap2) when DNA repair is made after $\mathrm{S}$ phase and before mitosis, M phase (mitosis), when cell and nuclear division occurs, and GO phase, when a cell leaves the cell cycle and requires longer (than G1 phase), or may completely loose the ability, to restart $S$ phase. 

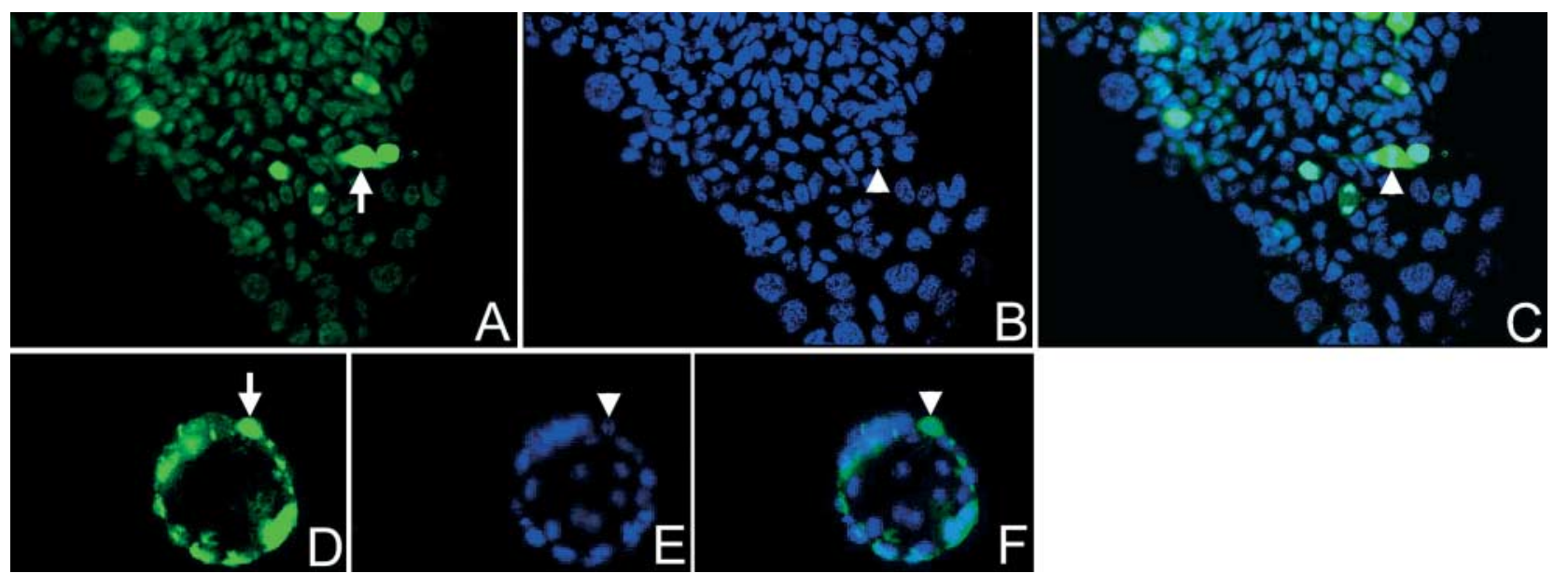

Figure 2 Threonine (Thr) phospho is detected at elevated levels in TSC at mitosis. TSC were cultured, fixed, and developed by immunocytochemical means for Thr phospho. (A, B, C) TSC stained with Thr phospho stain, Hoechst stain, and after merging respectively. TSC in apparent metaphase with elevated expression localized in the apparent mitotic spindle are shown by an arrow in A and arrowheads in B and C. (D, E, F) E3.5 embryos stained with Thr phospho stain, Hoechst stain, and after merging respectively. Arrow (in D) shows position of nucleus and arrowheads (in $\mathrm{E}, \mathrm{F}$ ) show nucleus.

(RSK1, Wang et al. 2004). However, the elevation in fluorescence intensity in a fraction of the cells in embryos occurred only for those antibodies that also showed an elevation of fluorescence intensity in obviously mitotic HTR and TSC. In addition, the fraction of nuclei of TSC, HTR, or embryos that had an elevated fluorescence intensity was in the range of $1-4 \%$ (data not shown), corresponding to the predicted fraction of unperturbed cells that would be in $\mathrm{M}$ phase (or some segment of M-phase) for $1 \mathrm{~h}$ or less $/ 24 \mathrm{~h}$ cell cycle.

The majority of proteins studied had elevated phosphorylation only at $M$ phase as indicated by obvious morphologic criteria. It is interesting to note that a few proteins with elevated fluorescence had additional non-M phase fluorescence (Table 2; p53 phospho SER15, supplemental Fig. 3) or the fluorescence was elevated during cell cycle phases besides the $M$ phase (Table 2; p57, Ets2, supplemental Figs 4 and 5 respectively). This is in agreement with previous studies that showed that p53 phospho SER15 is highest in cyclic somatic cells in early G1 phase (Buschmann et al. 2000), and that p57 is activated during endocycle $S$ phase and during the terminal G1 phase of mitotic trophoblasts (Zhang et al. 1998, Hattori et al. 2000).

The location of phosphoproteins elevated during mitosis is tabulated in Table 3. The majority of phosphoproteins were detected in the spindle complex, but p38MAPK phospho was detected in the spindle pole, and $\mathrm{Cdx} 2$ was localized with the DNA. This suggests, since many of the phosphoproteins are in the MAPK pathway, that MAPK may be involved with the regulation of the embryonic spindle complex, consistent with a role for MEK-MAPK in mitosis in Swiss 3T3 cells (Willard \& Crouch 2001). Note that the implied mitotic function of a given phosphoprotein may change quickly over developmental time, as we could find no elevated MAPK phospho during mitosis in preimplantation embryos using four anti-MAPK phospho antibodies, although this has been reported in postimplantation embryos (Corson et al. 2003). Although the great majority of this study was undertaken in reviewing large numbers of micrographs of unperturbed cultured placental cells and embryos, we did perform one study with a commercial colcemid analog, Karyomax. We found that, as in some other cell types (manufacturer's notes), overnight incubation of TSC with Karyomax elevated the fraction of cells with condensed, smaller, circular nuclei that were putative late G2/prophase. Normally, MEK1, 2 phospho was elevated and detected in cells in metaphase or anaphase where it appeared to be in the spindle complex, or in a very small fraction of cells with condensed nuclei where phosphoprotein was detected as spots on the DNA (Fig. 3A, B, C, supplemental Fig. 7). The Karyomax protocol also elevated the fraction of cells with elevated fluorescence for MEK1, 2 phospho (Fig. 3G, H, I, supplemental Fig. 7) and p27 phospho (Fig. 3J, K, L, supplemental Fig. 7). Interestingly, this treatment also created similar 1-, 2-, and 4-spotted circular nuclei that were correlated with TSC sheet dispersion and nuclear size increase, suggesting that the differentiation state of trophoblast cells might correlate with MEK1,2 and p27 expression around $\mathrm{M}$ phase. This brief study produced the desired result of increasing the fraction of cells with elevated phosphoprotein expression at or around $M$ phase. However, the lack of metaphase block in this cell type, and the inability to associate localization of nuclear spots with function in unperturbed cells, led us to discontinue this avenue of $M$ phase testing. It is interesting to note that (1) possible co-localization of p27 and MEK1,2 might suggest an enzyme substrate interaction, and (2) at a very low frequency MEK1,2 nuclear spots were seen in unperturbed TSC. Point number (2) suggests that the localization in the DNA may not be an artifact of tubulin 


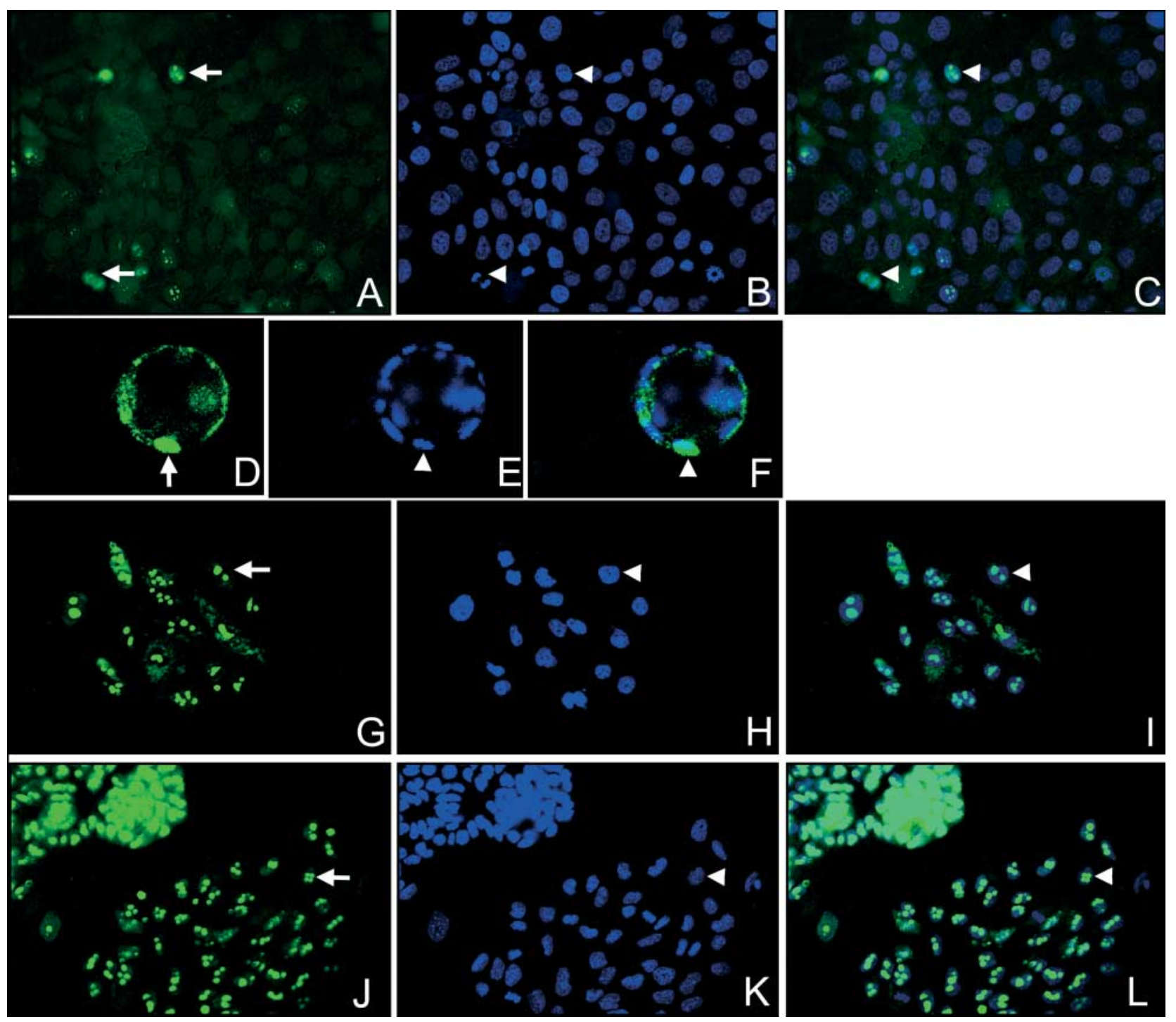

Figure 3 MEK1, 2 phospho and p27 phospho proteins are detected at elevated levels in TSC and E3.5 embryos at mitosis. MEK1, 2 phospho proteins are detected at elevated levels in TSC and E3.5 embryos at apparent prophase and anaphase mitosis. TSC were cultured, fixed, and developed by immunocytochemical means for MEK1, 2 phospho. (A, B, C) TSC stained with MEK1, 2 phospho stain, Hoechst stain, and after merging respectively. TSC in apparent anaphase with elevated expression localized in the mitotic spindle are shown by the bottom arrow in A while the top arrow shows a putative prophase cell MEK1, 2 phospho spots on the DNA. Corresponding arrowheads show nuclear position in B and C. (D, E, F) E3.5 embryos stained with MEK1, 2 phospho stain, Hoechst stain, and after merging respectively. (G, H, I) Uniform nuclear spotting of MEK1, 2 phospho in Karyomax-treated TSC corresponding to Hoechst stain, and after merging respectively. (J, K, L) Karyomax-treated TSC stained with p27 phospho stain, Hoechst stain, and after merging respectively. Arrows and arrowheads in D-L show position of nuclei.

depolymerization caused by Karyomax, but may reflect a low frequency event in unperturbed cells. This suggests that the proper colchicine derivative might be used in studies of $M$ phase function of phosphoproteins in TSC and embryos.

To quantitate the elevation in fluorescence intensity at $M$ phase, we performed a comparison of the levels of intensity of mitotic cells compared with interphase cells (Table 4). All phosphoproteins had a higher intensity at $M$ phase than in interphase cells, in the range of 1.5-5.6 (mean $=2.8)$ for ratios of raw quantitated immunofluorescence to 2.0-6.2 (mean $=3.8$ ) for the same ratios after a no-antibody background was subtracted from both the means for the $M$ phase (numerator) and interphase (denominator). In baseline studies for each antibody, it was shown that the fluorescence for each antibody was hgiher than with no-antibody, non-immune serum, or for antibody with co-addition of excess immunizing antigen (data not shown). One weakness of the study is that the pictures were taken by different individuals and they had a tendency to shoot micrographs on the high or low intensity range of the $0-255$ units/pixel intensity range of the Simple $\mathrm{PCl}$ software. The micrographs were taken to emphasize the differences between interphase and $M$ phase fluorescence. In baseline studies for each antibody, it was shown that the fluorescence for each antibody was 


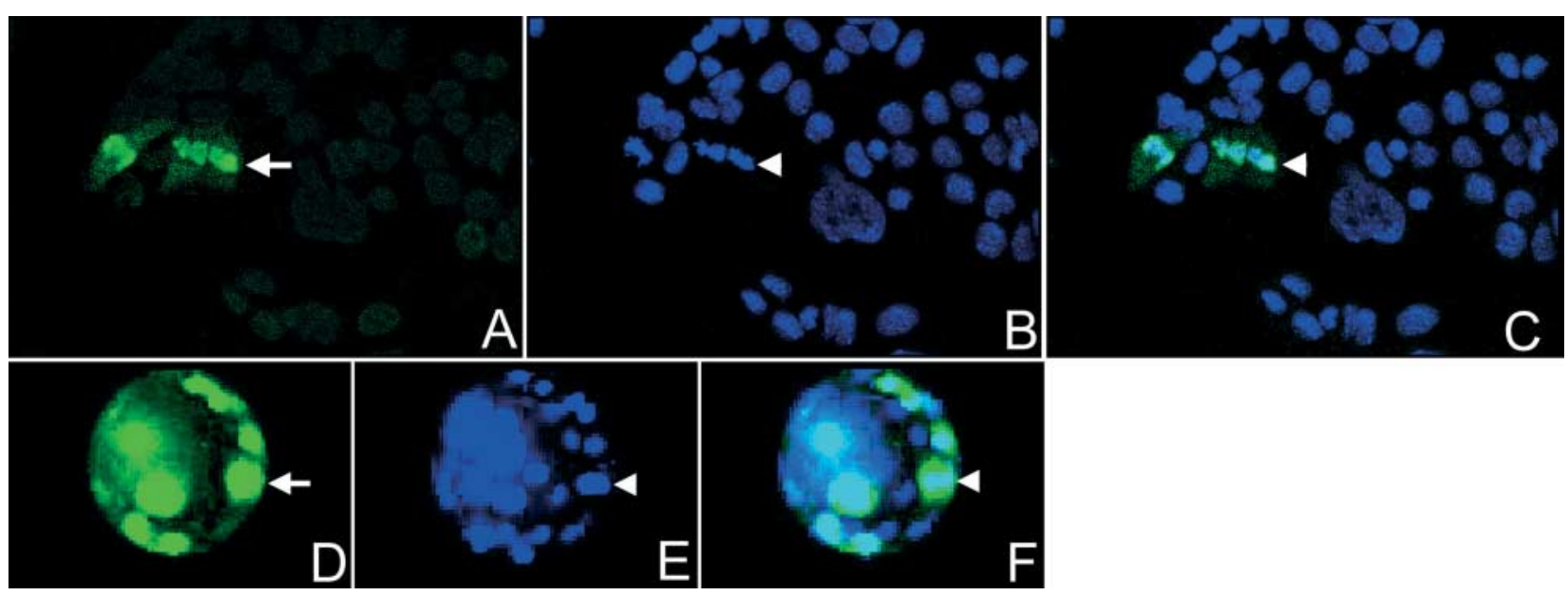

Figure 4 RSK1 phospho is detected at elevated levels in TSC and E3.5 embryos at mitosis. TSC were cultured and E3.5 embryos were isolated and fixed and developed by immunocytochemical means for RSK1 phospho. (A, B, C) TSC in apparent anaphase with elevated expression localized in the mitotic spindle. (D, E, F) Elevated expression of RSK1 phospho is detected in E3.5 embryos in mitotic cells, with condensed chromosomes and in apparent anaphase. Arrowheads (B, C, E, F) show nuclei and arrows (A, D) show position of nucleus.
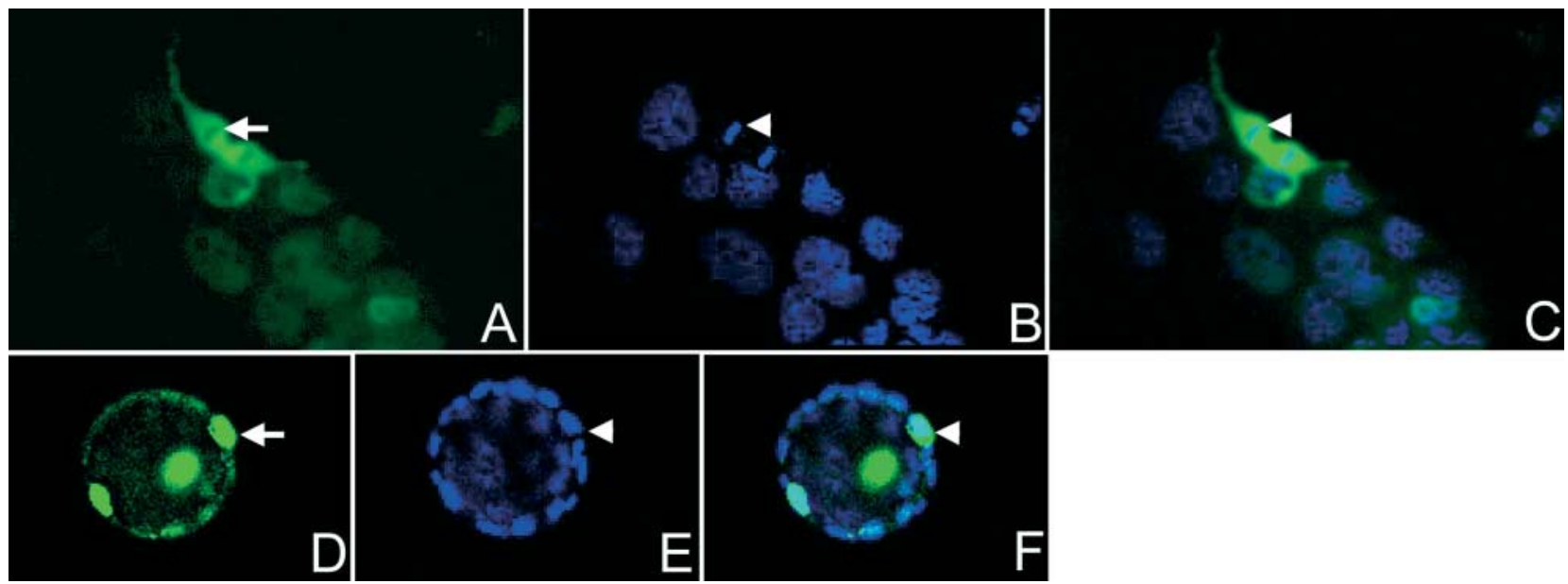

Figure 5 RSK3 phospho is detected at elevated levels in TSC and E3.5 embryos at mitosis. TSC were cultured and E3.5 embryos were isolated and fixed and developed by immunocytochemical means for RSK3 phospho. (A, B, C) TSC stained by RSK3 phospho stain, Hoechst stain, and after merging respectively, showing TSC in telephase with elevated expression colocalized with the reforming cytoplasm. (D, E, F) E3.5 embryos stained with RSK3 phospho stain, Hoechst stain, and after merging respectively, showing elevated expression in mitotic cells, with condensed chromosomes, Arrows in A and D show positions of nuclei, and arrowheads in B, C, E, F show nuclei.

higher than with no-antibody, non-immune serum, or for antibody with co-addition of excess immunizing antigen (data not shown). The high end of the fluorescence range is not linear due to pixel saturation and so the ratios may be an underestimate of the intensity of M-phase fluorescence and the corresponding fractions of protein populations that are phosphorylated.

\section{Discussion}

A little under half of serine-threonine kinases and transcription factors have a high level of phosphorylation at $M$ phase. Although this is a small sample size, it seems likely that these fractions may extend to yet-to-be tested transcription factors and kinases.

Mitosis requires a large reorganization of the cellular cytoskeleton. Microtubules are reorganized to form a bipolar spindle; the chromosomes become condensed, attach to the spindles at their kinetochores and are segregated into two daughter cells. Reorganization of the mitotic cytoskeleton requires a large, rapid surge of serine-threonine protein phosphorylation, controlling signaling events that coordinate mitotic processes. Our data (Fig. 2) are consistent with the increase in all threonine phosphorylation substrates at $M$ phase. An important trigger of the phosphorylation surge is the cyclin-dependent kinase (CDK), Cdc2. After CDK is activated, mitotic 

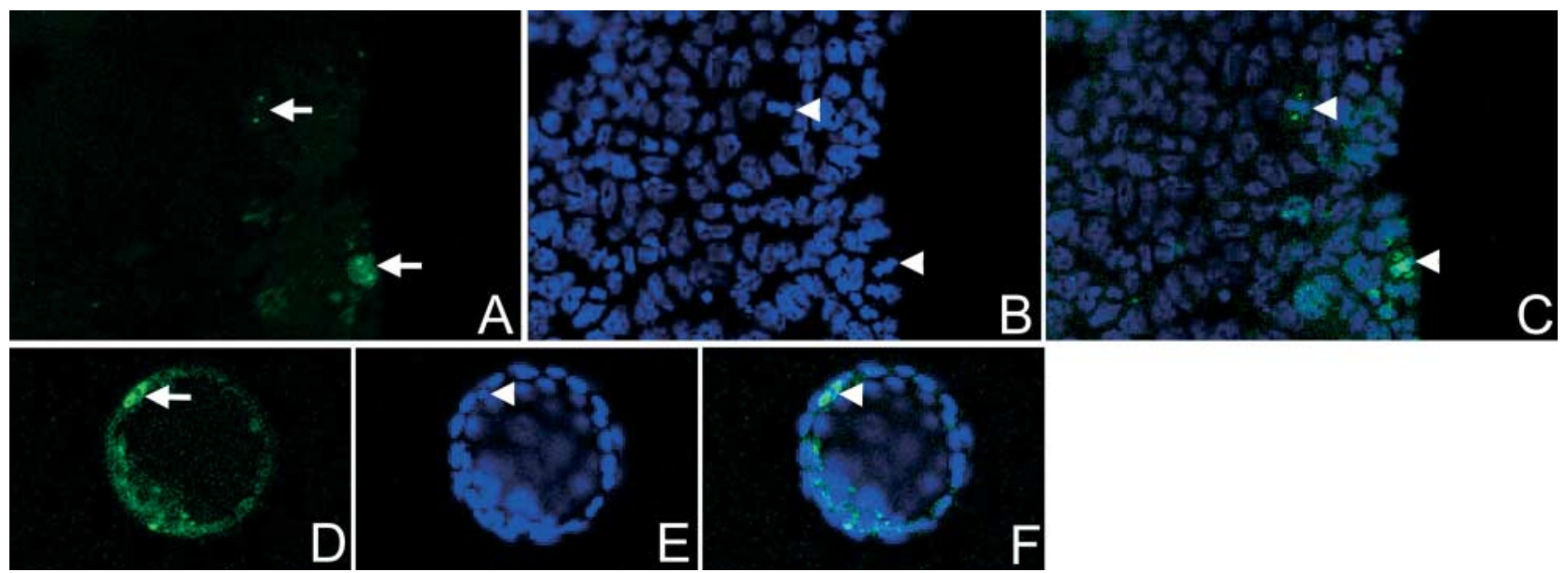

Figure 6 p38MAPK phospho proteins are detected at elevated levels in TSC and E3.5 embryos at mitosis. (A, B, C) TSC in metaphase with elevated expression of p38MAPK phospho in spindle poles. (D, E, F) Elevated expression of p38MAPK phospho is detected in E3.5 embryos in a mitotic cell, with condensed chromosomes. Arrowheads (B, C, E, F) show nuclei and arrows (A, D) show the position of the nuclei.
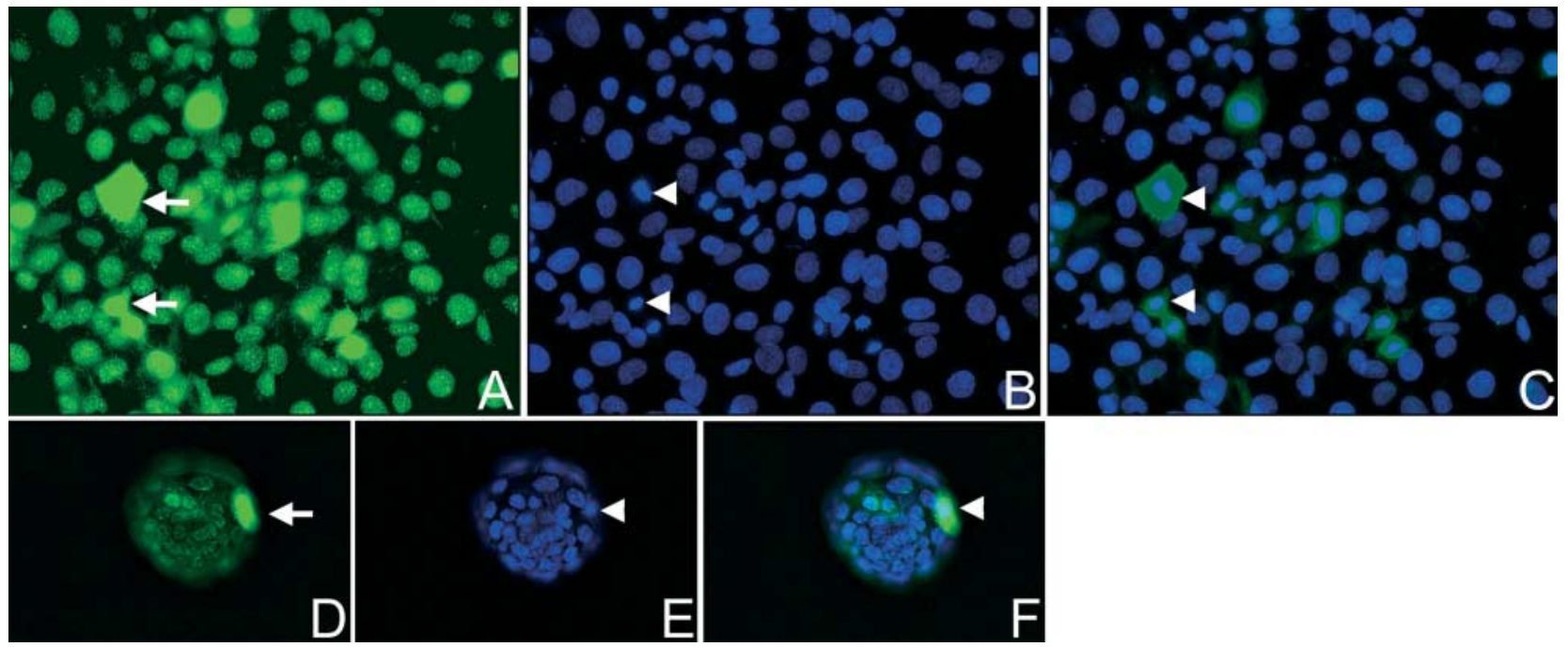

Figure 7 MycC phospho proteins are detected at elevated levels in TSC and E3.5 embryos at mitosis. (A, B, C) TSC in metaphase, anaphase, and telophase with elevated expression of $\mathrm{MycC}$ phospho localized in the mitotic spinctle. (D, E, F) Elevated expression of MycC phospho is detected in E3.5 embryos in mitotic cells, with condensed chromosomes. Arrowheads (B, C, E, F) show nuclei and arrows (A, D) show position of the nuclei.

serine/threonine kinases in three families - the polo kinases, aurora kinases and the NIMA-related kinases (Nrk) - govern mitosis (Piwnica-Worms 1996, O'Connell et al. 2003). These mitosis-specific enzymes may also control enzymes recruited from other pathways that function during interphase. For example, phosphatidylinositol3 kinase (PI3Kinase), 3-phosphoinositide-dependent protein kinase (PDK), Akt1 (Dangi et al. 2003), CDK2 (Doree \& Galas 1994), MycC (Niklinski et al. 2000), Raf1, MEK1,2, MAPK1,2 and RSK1, 2, 3 (Willard \& Crouch 2001) are involved with $M$ phase in somatic cells, and in G1-S phase signaling (Sears et al. 2000, Wilkinson \& Millar 2000, Rappolee 2003). The entire MAPK pathway is detected in preimplantation mouse embryos (Wang et al. 2004, Xie et al. 2004). Little work has been done on the interaction of the MAPK pathway with the three mitosis-specific enzyme families during mitosis. But, during meiosis, MAPK can be upstream of polo-like kinase in starfish oocytes (Okano-Uchida et al. 2003), MAPK can regulate NIMA-related kinases in mouse spermatogenesis (Di Agostino et al. 2002), but MAPK pathway is apparently independent of aurora kinases in frog oocytes (Maton et al. 2003). This is the first report of high levels of expression for these MAPK pathway phosphoproteins in late preimplantation embryos and placental cells at $M$ phase. These data are consistent with a putative $M$ phase function of MAPK pathway enzymes in early placental lineage cells.

It is important to keep these findings in mind when planning experiments and interpreting data regarding 

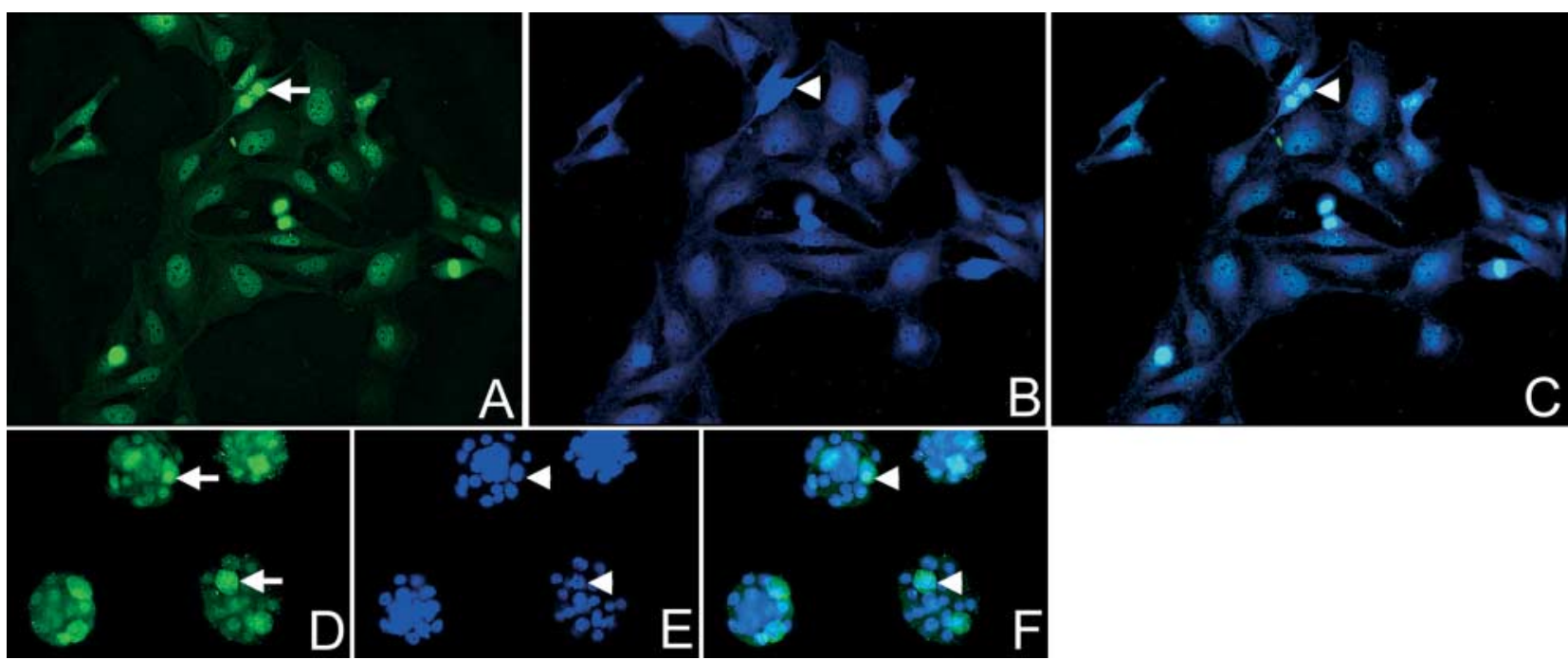

Figure $8 \mathrm{Cdx}$ phospho proteins are detected at elevated levels in HTR and E3.5 embryos at mitosis. (A, B, C) HTR in metaphase and anaphase with elevated expression of $\mathrm{Cdx}$ phospho localized with DNA. (D, E. F) Elevated expression of Cdx phospho is detected in E3.5 embryos in mitotic cells, with condensed chromosomes. Note that these embryos are not at the same scale as in Figs $2-7$. The arrow on top of $A$ shows a cell at anaphase, the arrow at the botton of A shows a cell at metaphase. The arrows at D show positions of nuclei, arrowheads in B, C, E, F show nuclei.

\section{G2}
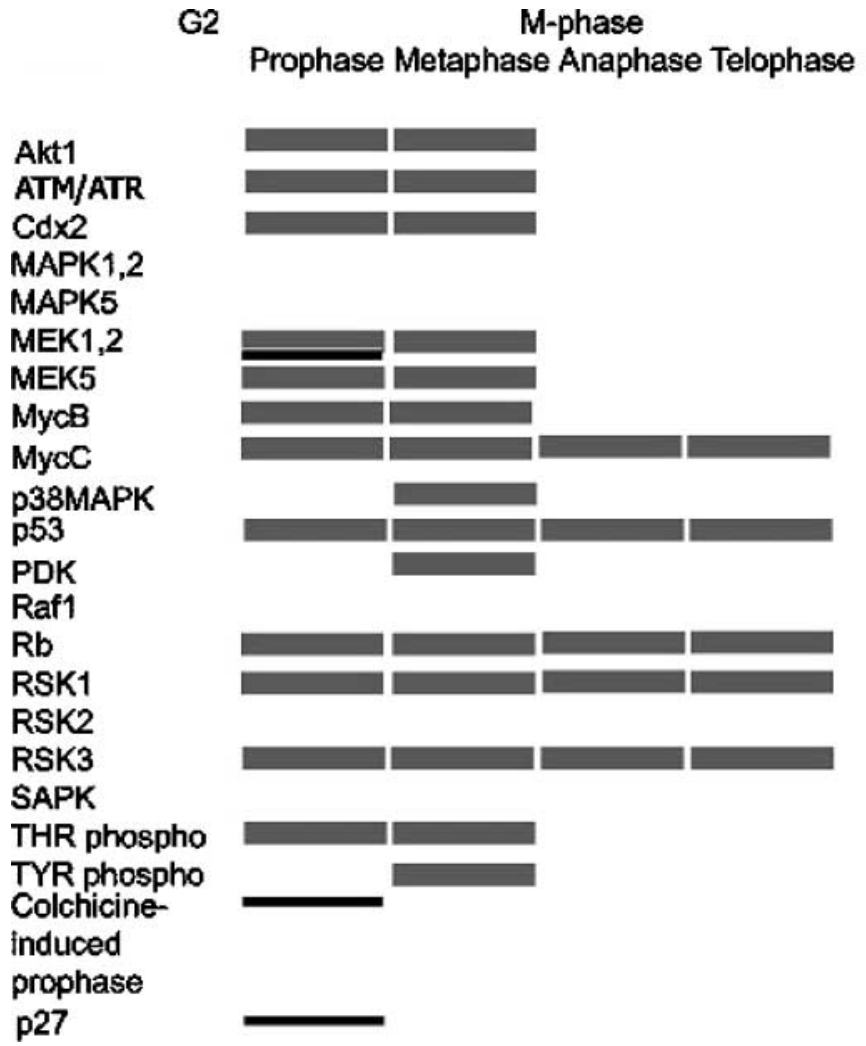

G1-S phase decision making in the early embryo. If measuring induction of interphase responses to growth factors by kinases or transcription factors using quantitative immunofluorescence, elevated fluorescence in mitotic cells ('mitotic hotspots') should be avoided. Alternatively, attempts can be made to synchronize cell divisions in order to avoid M phase. Similarly, if loss-of-function perturbations are performed, investigators should be alert for

\section{Embryo M-phase}

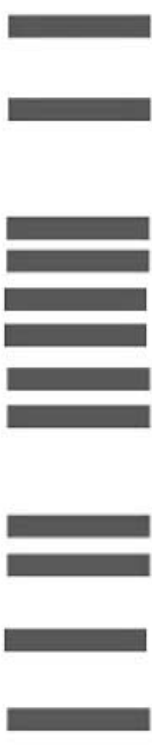

Figure 9 Summary of temporal expression of threonine-serine kinases and transcription factors that are phosphorylated at high levels during mitosis. Large grey boxes represent three M-phase segments when fluorescence intensity is elevated in normal cells, and smaller black rectangles show additional effects in colchicine/Karyomax-treated cells.

M phase phenotypes. An additional consideration is that alternative functions of the enzyme or transcription factor besides those controlling G1-S phase progression may also occur during G1-S phase.

The mitotic function of kinases changes during development. It is suggested, for example, that MEK1, 2 function is required for $M$ phase completion as the MEK1, 2, 5 inhibitor, U0126, can block mitosis (Willard \& Crouch 
Table 1 Signaling enzymes that have elevated phosphorylation during mitosis: intermediary serine- threonine kinases signal transduction proteins.

\begin{tabular}{lll}
\hline Protein & Antibody* & Cell type \\
\hline Akt1 phospho & SC1618* & M phase** \\
Akt phospho & SC5298 & HTR, TSC, embryo \\
ATM phospho & CS4526 & TSC \\
MEK1,2 all forms & CS9122* & HTR, embryo \\
MEK1,2 phospho & CS9121* & TSC, HTR, embryo \\
MEK5 all forms & SC10795* & TSC, HTR, embryo \\
PDK phospho & CS3061* & TSC, HTR, embryo \\
RSK1 phospho & CS9344* & HTR, embryo \\
RSK3 phospho & CS9345* & TSC, HTR, embryo \\
p38MAPK all forms & CS9212* & TSC, HTR, embryo \\
p38MAPK phospho & CS9211* & TSC, HTR, embryo \\
CDK2 phospho & CS2561* & TSC, HTR, embryo \\
FGFR1 phospho & SC12935 & HTR, embryo \\
GSK3alpha phospho & CS9331 & TSC, HTR, embryo \\
MAPK1,2 phospho & CS9101* & HTR, embryo \\
MAPK1,2 phospho & M8159* & TSC, HTR, embryo \\
MAPK1,2 phospho & CS9106* & TSC, HTR, embryo \\
MAPK1,2 phospho & UBI $06-624 *$ & TSC, HTR, embryo \\
ERK5, phospho & CS3371* & TSC, HTR, embryo \\
Raf1 phospho & CS9421* & HTR, embryo \\
Raf1 phospho & SC7198* & TSC, HTR, embryo \\
Raf1,2 phospho & SC12358 & TSC, HTR, embryo \\
SAPK phospho & CS9251* & HTR, embryo \\
SAPK all forms & CS9251* & TSC, HTR, embryo \\
\hline
\end{tabular}

*Western blots showed a single or major band of the correct size from lysates of TSC or HTR (Wang et al. 2004, Xie et al. 2004) (not shown). ** + Signifies that elevated fluorescence intensity in apparent mitotic cells was detected, and - signifies that elevated fluorescence intensity in apparent mitotic cells was never detected.

2001). Therefore, MEK seems to be a dominant G1-S phase kinase used at M phase, but MAPK seems not to be as important in somatic cells (Harding et al. 2003) or in mouse embryos during $M$ phase of the first two cleavage divisions (Iwamori et al. 2000). Our data are in agreement with these reports. Like the 1 - to 4-cell stage embryo (Iwamori et al. 2000), MEK1, 2 participates in M phase later in preimplantation development as shown by immunocytochemical means. In contrast to the 1- to 4-cell stage embryos, Raf1 is not highly phosphorylated during $M$ phase in later stage preimplantation embryos or in TSC and HTR. Dissimilar to our data and that of Iwamori and colleagues, MAPK phospho is elevated in post-implantation embryos at $M$ phase (Corson et al. 2003). It seems that the embryo may use different sets of kinases at $M$ phase during different phases of development. Therefore, an additional caution may be that the data presented here may apply to preimplantation development, but each researcher may have to re-examine the expression of these kinases and transcription factors during each period of embryonic development studied.

This study was based upon a large scan of proteins and phosphoproteins using 153 antibodies and 49 phospho-specific antibodies in 'unperturbed' embryos ex vivo, and placental TSC and HTR cultured under normal proliferation-promoting conditions. Approximately, 60000 fluorescence micrographs were recorded, allowing low frequency, short-duration events such as metaphase or anaphase a good opportunity to be observed. Since the preimplantation embryo is translucent and small (having less than 100 cells through E3.5), it lends itself to immunocytochemistry more than to Western blot analysis. In this study, we focused on a mini-proteomics approach where immunocytochemistry was performed in embryos and cell lines. In other studies (Wang et al. 2004, Xie et al. 2004, data not shown), Western blots were analyzed for TSC and HTR, cell lines that represent about $75 \%$ of cells in the E3.5 embryo, and the antibodies tested in TSC or embryos are indicated in Tables 1 and 2. A weakness of this study is that Western blots were not performed in the embryos themselves. Such a study would be very prohibitive in cost. A strength of this study is that 29 of the proteins reported here had at least two antibodies that yielded similar results, and that all phosphoproteins, except p53, had similar frequencies of cells with elevated phosphoprotein fluorescence in TSC/HTR as in embryos. In the case of p53, elevated p53 occurred during obvious $M$ phase and also during other apparent cell cycle phases. This made these results difficult to interpret as HTR is transgenic for SV40 large T antigens and this transforming may affect p53 stability and the dynamics of phosphorylation (Graham et al. 1993, Meek 2002). In addition, TSC may partially represent a period of placental lineage development slightly after preimplantation development. All the antibodies with no elevated phosphoprotein fluorescence in TSC/HTR also had no elevated phosphoprotein fluorescence in embryos. The congruence of negative and positive findings for elevation of phosphoproteins at $M$ phase was complete for TSC/HTR compared with embryos except for one phosphoprotein. 
Table 2 Transcription factors and other proteins that have elevated phosphorylation during mitosis.

\begin{tabular}{|c|c|c|c|}
\hline Protein & Antibody & Cell type & M phase \\
\hline \multicolumn{4}{|l|}{ Transcription factors } \\
\hline ATF2 phospho & CS9221 & HTR, TSC, embryo & - \\
\hline Elk1 phospho & CS9186 & TSC, embryo & - \\
\hline JunC phospho & CS9261* & HTR, TSC, embryo & - \\
\hline STAT1 phospho & CS9171 & TSC, embryo & - \\
\hline Ets2 all forms & SC351* & TSC, HTR, & - (only putative $\mathrm{S}$ phase)* \\
\hline Cdx2 phospho & Rings et al. ${ }^{\mathrm{a}}$ & HTR, embryo & + \\
\hline MycB phospho & SC16303* & TSC, HTR, embryo & + \\
\hline MycC phospho & SC $8000 *$ & TSC, HTR, embryo & + \\
\hline \multicolumn{4}{|c|}{ Phospho-protein substrates (sub) and others } \\
\hline TYR phospho sub & SC18182 & TSC, embryo & + \\
\hline THR phospho sub & SC9381 & TSC, embryo & + \\
\hline Akt1 phospho sub & CS9611 & HTR, embryo & + \\
\hline ATM phospho sub & CS2851 & HTR & + \\
\hline PKA phospho sub & CS9621 & HTR & + \\
\hline $\mathrm{Rb}$ phospho & CS9301* & TSC, HTR, embryo & + \\
\hline Rb phospho & SC7986R* & TSC, HTR, embryo & + \\
\hline PDK phospho sub & CS2291 & HTR & + \\
\hline p53 phospho & SC11764* & HTR & $+(+$ putative $\mathrm{G} 1$ phase $) * * *$ \\
\hline p57 all forms & SC8298 & TSC, HTR & $-(\text { only S phase })^{* *}$ \\
\hline p57KIP2 & MS-1062-P0 & TSC, HTR & - (only S phase)** \\
\hline p21 phospho SER146 & SC12902R & HTR, embryo & - \\
\hline p21WAF1 & MS-387-P0 & HTR, embryo & - \\
\hline p21WAF1 & MS-387-P0 & HTR, embryo & - \\
\hline p27 phospho & SC12939R & HTR, embryo & - \\
\hline p27KIP1 & MS-256-P0 & HTR, embryo & - \\
\hline Estrogen R- $\alpha$ phospho & CS2514 & HTR, embryo & - \\
\hline Estrogen R- $\alpha$ phospho & CS2515 & HTR, embryo & - \\
\hline PKC phospho sub & CS2261 & HTR, embryo & - \\
\hline $14-3-3$ sub & CS9601 & HTR, embryo & - \\
\hline FRS2alpha phospho & CS3861* & HTR, embryo & - \\
\hline
\end{tabular}

* Western blots showed a single or major band of the correct size from lysates of TSC or HTR (not shown).

** Similar distribution in fraction of cells and morphogenetic identity of nuclei as observed previously for p57 as cells leave cytokinetic proliferation and enter endoreduplication in late G1 (Zhang et al. 1998, Hattori et al. 2000).

*** Similar distribution in fraction of cells and morphogenetic identity of nuclei as suggested for p53 phospho SER15 for largest activation during G1 phase (Buschmann et al. 2000).

a (Rings et al. 2001).

Table 3 Cellular location of phosphorylated threonine-serine kinases and transcription factors at mitosis.

\begin{tabular}{ll}
\hline Protein & Location at M phase \\
\hline Serine-threonine protein kinases & \\
Akt1 phospho & Mitotic spindle colocalization \\
MEK1, 2 all forms & Mitotic spindle colocalization at metaphase, 2 spots on DNA with colchicine at putative prophase* \\
MEK1, 2 phospho & Mitotic spindle colocalization at metaphase, 2 spots on DNA with colchicine at putative prophase* \\
MEK5 all forms & Mitotic spindle colocalization \\
RSK1 phospho & Mitotic spindle colocalization, DNA \\
RSK3 phospho & Mitotic spindle colocalization \\
p38MAPK all forms & Mitotic spindle, pole \\
p38MAPK phospho & Mitotic spindle, pole \\
Transcription factors & \\
Cdx2 phospho & Condensed DNA colocalization \\
MycB phospho & Mitotic spindle colocalization \\
MycC phospho & Mitotic spindle colocalization \\
Other proteins & \\
TYR phospho sub & Mitotic spindle \\
THR phospho sub & Mitotic spindle, pole \\
ATM phospho sub & Mitotic spindle \\
Akt1 phospho sub & Mitotic spindle \\
p27 & $1-4$ spots on DNA with colchicine; similar spots at very low frequency in unperturbed cells* \\
Rb phospho & Mitotic spindle \\
\hline
\end{tabular}

* Note that these double spots also occur at very low frequencies in normal TSC, untreated by colchicine/Karyomax. This suggests that the spotting is not an artifact of Karyomax, but a trapping of a low frequency event whose frequency is increased by Karyomax.

sub, substrate. 
Table 4 Increase in phosphorylated threonine-serine kinases and transcription factors at mitosis.

\begin{tabular}{|c|c|c|c|c|}
\hline $\begin{array}{l}\text { Gene product } \\
(n=M \text {-phase, } n=\text { interphase })\end{array}$ & $\begin{array}{c}\text { M-phase intensity } \\
\text { mean } \pm \text { S.D. (no antibody) }\end{array}$ & $\begin{array}{l}\text { Interphase intensity } \\
\text { mean } \pm \text { S.D. (no antibody) }\end{array}$ & $P$ value & $\begin{array}{l}\text { Stimulation Index } \\
\text { (SI)/SI -no antibody }\end{array}$ \\
\hline Akt phospho BWM $(4,12)$ & $143.8 \pm 12.2(120.4)$ & $77.4 \pm 10.1(44)$ & 0.0001 & $1.9 / 2.7$ \\
\hline Akt phospho TSC $(6,12)$ & $170.3 \pm 15.3(141.5)$ & $79.6 \pm 16.6(50.8)$ & $<0.0001$ & $2.1 / 2.8$ \\
\hline Akt substrate $\operatorname{HTR}(6,12)$ & $173.5 \pm 23.3(138.1)$ & $86 \pm 9.2(50.6)$ & 0.0001 & $2.0 / 2.7$ \\
\hline ATM/ATR subs. HTR $(6,12)$ & $186.1 \pm 26.4(150.7)$ & $82.7 \pm 7.0(47.3)$ & 0.0001 & $2.3 / 3.2$ \\
\hline Cdx2 phospho BWM $(4,12)$ & $156.3 \pm 12.8(126.4)$ & $83.1 \pm 7.7(53.2)$ & 0.006 & $1.9 / 2.4$ \\
\hline Cdx2 phospho HTR $(12,12)$ & $212.5 \pm 26.4(182.5)$ & $94.1 \pm 6.4(64)$ & $<0.0001$ & $2.3 / 2.9$ \\
\hline Ets2 (TSC) $(4,12)$ & $180.7 \pm 40.8$ & $32.3 \pm 9.6$ & 0.006 & 5.6 \\
\hline Ets2 (HTR) $(4,12)$ & $169.9 \pm 21.1$ & $42.3 \pm 5.9$ & 0.001 & 4.0 \\
\hline MEK1, 2 (BWM) $(4,12)$ & $60.2 \pm 11.1(45.1)$ & $37.4 \pm 8.2(22.3)$ & 0.02 & $1.6 / 2.0$ \\
\hline MEK 1,2 (HTR) $(8,12)$ & $238.0 \pm 39.5(211.3)$ & $65.2 \pm 12.9(38.5)$ & $<0.0001$ & $3.7 / 5.5$ \\
\hline MycB TSC $(6,12)$ & $208.1 \pm 17.9(190.6)$ & $70.5 \pm 12.1(53)$ & $<0.0001$ & $3.0 / 3.6$ \\
\hline MycB HTR $(6,12)$ & $200 \pm 16.6(165.9)$ & $81.3 \pm 8.8(47.2)$ & $<0.0001$ & $2.5 / 3.5$ \\
\hline МусB BWM $(6,12)$ & $101.6 \pm 20.3(68.1)$ & $67.7 \pm 15.2(32.2)$ & 0.007 & $1.5 / 2.1$ \\
\hline MycC TSC $(8,12)$ & $205.2 \pm 24.9(184.4)$ & $67.6 \pm 10.0(46.8)$ & $<0.0001$ & $3.0 / 3.9$ \\
\hline MycC HTR $(12,12)$ & $249 \pm 13.2(213.6)$ & $113.7 \pm 21.6(78.3)$ & $<0.0001$ & $2.2 / 2.7$ \\
\hline MycC BWM $(10,12)$ & $136.7 \pm 15.3(125.6)$ & $40.8 \pm 7.4(31.7)$ & $<0.0001$ & $3.4 / 4.0$ \\
\hline p38MAPK TSC $(5,12)$ & $74.3 \pm 9.0(58.8)$ & $44.0 \pm 9.9(28.5)$ & 0.0003 & $1.7 / 2.1$ \\
\hline p38MAPK BWM $(4,12)$ & $108.3 \pm 24.1(92.4)$ & $47.1 \pm 6.2(31.2)$ & 0.02 & $2.3 / 3.0$ \\
\hline p53 phospho TSC $(12,12)$ & $199.4 \pm 23.8(163.4)$ & $94.8 \pm 10.2(58.8)$ & $<0.0001$ & $2.1 / 2.8$ \\
\hline p53 phospho HTR $(12,12)$ & $215.6 \pm 19.5(194.2)$ & $66.9 \pm 5.4(45.4)$ & $<0.0001$ & $3.2 / 4.3$ \\
\hline p57 all forms TSC $(6,12)$ & $221.4 \pm 44.7(197.1)$ & $56.2 \pm 3.9(31.9)$ & $<0.0001$ & $3.9 / 6.2$ \\
\hline p57 all forms $\operatorname{HTR}(6,12)$ & $154.4 \pm 32.3(143.8)$ & $55.1 \pm 9.4(44.5)$ & $<0.0001$ & $2.8 / 3.2$ \\
\hline PDK phospho TSC $(6,12)$ & $151.7 \pm 31.2(126.2)$ & $60 \pm 19.7(34.5)$ & 0.003 & $2.5 / 3.7$ \\
\hline PDK substrate HTR $(4,12)$ & $125.3 \pm 20.5(89.9)$ & $63.1 \pm 6.3(27.7)$ & 0.01 & $2.0 / 3.2$ \\
\hline PKA phospho HTR $(4,12)$ & $140.2 \pm 33.5(116.1)$ & $56.1 \pm 8.4(32)$ & 0.02 & $2.5 / 3.6$ \\
\hline Rb phospho CS9301TSC $(6,12)$ & $211.2 \pm 18.2(192.4)$ & $56.0 \pm 6.3(37.2)$ & $<0.0001$ & $3.8 / 5.2$ \\
\hline Rb phospho SC7986 TSC $(6,12)$ & $165.0 \pm 14.6(143.0)$ & $46.2 \pm 3.5(24.2)$ & $<0.0001$ & $3.6 / 5.9$ \\
\hline Rb phospho SC7986 HTR $(6,12)$ & $194.7 \pm 25.6(162.7)$ & $60.5 \pm 4.7(28.5)$ & 0.0001 & $3.2 / 5.7$ \\
\hline RSK1 phospho TSC $(12,12)$ & $225.1 \pm 17.8(201.7)$ & $58.0 \pm 3.6(34.6)$ & $<0.0001$ & $3.9 / 5.8$ \\
\hline RSK1 phospho BWM $(10,12)$ & $239.8 \pm 25.0(217.1)$ & $69.9 \pm 15.1(42.2)$ & $<0.0001$ & $3.4 / 5.1$ \\
\hline RSK3 phospho TSC $(12,12)$ & $154.3 \pm 13.1(123.2)$ & $72.0 \pm 10.3(40.9)$ & $<0.0001$ & $2.1 / 3.0$ \\
\hline RSK3 phospho HTR $(12,12)$ & $195.7 \pm 22.5(161.3)$ & $61.6 \pm 7.2(26.2)$ & $<0.0001$ & $3.2 / 6.2$ \\
\hline RSK3 phospho BWM $(12,12)$ & $173.6 \pm 21.1(150.1)$ & $55.9 \pm 4.4(32.4)$ & $<0.0001$ & $3.1 / 4.6$ \\
\hline THR phospho BWM $(10,12)$ & $218.8 \pm 12.2(188.1)$ & $75.2 \pm 10.7(44.5)$ & $<0.0001$ & $2.9 / 4.2$ \\
\hline THR phospho TSC $(12,12)$ & $212.1 \pm 20.7(194.3)$ & $74.1 \pm 5.8(56.3)$ & $<0.0001$ & $2.9 / 3.5$ \\
\hline
\end{tabular}

$\mathrm{BWM}=$ blastocyst wholemount, $\mathrm{HTR}=$ human trophoblast cells, $\mathrm{TSC}=$ mouse trophoblast stem cells, subs $=$ substrate.

Several proteins had a unique $M$ phase localization. Cdx2 is, like aurora-B kinase, a cell cycle M-phase passenger (Higuchi \& Uhlmann 2003) that moves from centromeres to the spindle midzone during mitosis, functioning throughout mitosis in chromosome condensation and segregation (Adams et al. 2001).

p38MAPK was detected in the spindle poles. p38MAPK is detected throughout preimplantation mouse development (Zhong et al. 2004), and mediates mitosis during early Xenopus cleavage divisions and is located in the spindle pole (Takenaka et al. 1998). The majority of phosphoproteins were observed in the putative spindle complex.

In summary, this study shows that a little under half of the signaling enzymes and transcription factors studied had elevated levels of phosphorylation at $M$ phase in preimplantation mouse embryos and placental cell lines, suggesting that caution must be used in interpreting expression studies and cause-and-effect experiments aimed at testing the role of these phosphoproteins during G1 to $S$ phase decision making. The results also suggest that the studies primarily aimed at testing the role of these phosphoproteins in early embryo/placental $M$ phase function would also be of interest.

\section{Acknowledgements}

This research was supported by grants from the National Institute of Child Health and Human Development, NIH (R01 HD40972A) (D A R) and NASA (NRA, NAG 2150309). E H H M R is supported by a fellowship of the Royal Netherlands Academy of Arts and Sciences. We thank Mike Kruger for his help with statistics. We wish to thank Dr Randy Armant for helpful advice on fluorescent microscopy.

\section{References}

Adams RR, Carmena M \& Earnshaw WC 2001 Chromosomal passengers and the (aurora) ABCs of mitosis. Trends in Cellular Biology $1149-54$

Buschmann T, Adler V, Matusevich E, Fuchs SY \& Ronai Z 2000 p53 phosphorylation and association with murine double minute 2, c-Jun NH2-terminal kinase, p14ARF, and p300/CBP during the cell cycle and after exposure to ultraviolet irradiation. Cancer Research 60 896-900. 
Chai N, Patel $Y$, Jacobson K, McMahon J, McMahon A \& Rappolee DA 1998 FGF is an essential regulator of the fifth cell division in preimplantation mouse embryos. Developmental Biology 198 105-115.

Corson LB, Yamanaka Y, Lai KM \& Rossant J 2003 Spatial and temporal patterns of ERK signaling during mouse embryogenesis. Development 130 4527-4537.

Cross JC, Werb Z \& Fisher SJ 1994 Implantation and the placenta: key pieces of the development puzzle. Science 266 1508-1518.

Dangi S, Cha H \& Shapiro P 2003 Requirement for phosphatidylinositol-3 kinase activity during progression through S-phase and entry into mitosis. Cellular Signalling 15 667-675.

Di Agostino S, Rossi P, Geremia R \& Sette C 2002 The MAPK pathway triggers activation of Nek2 during chromosome condensation in mouse spermatocytes. Development 129 1715-1727.

Doree M \& Galas S 1994 The cyclin-dependent protein kinases and the control of cell division. FASEB Journal 8 1114-1121.

Graham CH, Hawley TS, Hawley RG, MacDougall JR, Kerbel RS, Khoo N \& Lala PK 1993 Establishment and characterization of first trimester human trophoblast cells with extended lifespan. Experimental Cell Research 206 204-211.

Harding A, Giles N, Burgess A, Hancock JF \& Gabrielli BG 2003 Mechanism of mitosis-specific activation of MEK1. Journal of Biological Chemistry 278 16747-16754.

Hattori N, Davies TC, Anson-Cartwright L \& Cross JC 2000 Periodic expression of the cyclin-dependent kinase inhibitor p57(Kip2) in trophoblast giant cells defines a G2-like gap phase of the endocycle. Molecular Biology of the Cell 11 1037-1045.

Higuchi T \& Uhlmann F 2003 Cell cycle: passenger acrobatics. Nature 426 780-781.

Hogan B, Beddington R, Constantini F \& Lacy B 2002 Manipulating the Mouse Embryo, A Laboratory Manual. Cold Spring Harbor: Cold Spring Harbor Laboratory.

Iwamori N, Naito K, Sugiura K, Kagii H, Yamashita M, Ohashi S, Goto S, Yamanouch K \& Tojo H 2000 Phosphorylation of mitogenactivated protein kinase cascade during early embryo development in the mouse. Reproduction, Fertility, and Development 12 209-214.

Maton G, Thibier C, Castro A, Lorca T, Prigent C \& Jessus C 2003 Cdc2-cyclin B triggers $\mathrm{H} 3$ kinase activation of Aurora-A in Xenopus oocytes. Journal of Biological Chemistry 278 21439-21449.

Meek DW 2002 p53 Induction: phosphorylation sites cooperate in regulating. Cancer Biology and Therapy 1 284-286.

Niklinski J, Claassen G, Meyers C, Gregory MA, Allegra CJ, Kaye FJ, Hann SR \& Zajac-Kaye M 2000 Disruption of Myc-tubulin interaction by hyperphosphorylation of $\mathrm{c}-\mathrm{Myc}$ during mitosis or by constitutive hyperphosphorylation of mutant c-Myc in Burkitt's lymphoma. Molecular and Cellular Biology 20 5276-5284.

O'Connell MJ, Krien MJ \& Hunter T 2003 Never say never. The NIMA-related protein kinases in mitotic control. Trends in Cell Biology 13 221-228.

Okano-Uchida T, Okumura E, Iwashita M, Yoshida H, Tachibana K \& Kishimoto T 2003 Distinct regulators for Plk1 activation in starfish meiotic and early embryonic cycles. $E M B O$ Journal 22 $5633-5642$.

Pedersen RA 1987 Experimental Approaches to Mammalian Embryonic Development. Cambridge: Cambridge University Press.

Piwnica-Worms H 1996 Reversible phosphorylation and mitotic control. Journal of Laboratory and Clinical Medicine $\mathbf{1 2 8}$ 350-354.

Rappolee DA 1999 It's not just baby's babble/Babel: recent progress in understanding the language of early mammalian development: a minireview. Molecular Reproduction and Development 52 234-240.

Rappolee DA 2003 Signal transduction. In Introduction to Bioinformatics. A Theoretical and Practical Approach, pp 55-71. Eds S Krawetz \& D Womble. Totowa, NJ: Humana Press.

Rings EH, Boudreau F, Taylor JK, Moffett J, Suh ER \& Traber PG 2001 Phosphorylation of the serine 60 residue within the $\mathrm{Cdx} 2$ activation domain mediates its transactivation capacity. Gastroenterology 121 1437-1450.

Roovers K \& Assoian RK 2000 Integrating the MAP kinase signal into the G1 phase cell cycle machinery. Bioessays 22 818-826.

Sears RC \& Nevins JR 2002 Signaling networks that link cell proliferation and cell fate. Journal of Biological Chemistry 277 11617-11620.

Sears R, Nuckolls F, Haura E, Taya Y, Tamai K \& Nevins JR 2000 Multiple Ras-dependent phosphorylation pathways regulate Myc protein stability. Genes and Development 14 2501-2514.

Takenaka K, Moriguchi T \& Nishida E 1998 Activation of the protein kinase p38 in the spindle assembly checkpoint and mitotic arrest. Science 280 599-602.

Tanaka S, Kunath T, Hadjantonakis AK, Nagy A \& Rossant J 1998 Promotion of trophoblast stem cell proliferation by FGF4. Science 282 2072-2075.

Uitenbroek DG 1997 SISA Binomial. http://home.clara.net/sisa/ binomial.htm

Wang Y, Wang F, Sun T, Barisic D, Trostinskaia A, Wygle D, Puscheck E \& Rappolee DA 2004 Entire mutagen activated protein kinase (MAPK) pathway is present in preimplantation mouse embryos. Developmental Dynamics 231 72-87.

Whitmarsh AJ \& Davis RJ 1999 Signal transduction by MAP kinases: regulation by phosphorylation-dependent switches. Science's Signal Transduction Knowledge Environment (online) PE1.

Whitmarsh AJ \& Davis RJ 2000 Regulation of transcription factor function by phosphorylation. Cellular and Molecular Life Science $571172-1183$.

Wilkinson MG \& Millar JB 2000 Control of the eukaryotic cell cycle by MAP kinase signaling pathways. FASEB Journal $\mathbf{1 4}$ 2147-2157.

Willard FS \& Crouch MF 2001 MEKERK, and p90RSK are present on mitotic tubulin in Swiss 3T3 cells: a role for the MAP kinase pathway in regulating mitotic exit. Cell Signalling $\mathbf{1 3}$ 653-664.

Xie Y, Wang T, Sun T, Wang F, Trostinskaia A, Puscheck EE \& Rappolee DA 2004 Six post-implantation lethal knockouts of genes for lipophilic MAPK pathway proteins are expressed in preimplantation mouse embryos and trophoblast stem cells. Molecular Reproduction and Development (In Press).

Zhang P, Wong C, DePinho RA, Harper JW \& Elledge SJ 1998 Cooperation between the Cdk inhibitors p27(KIP1) and p57(KIP2) in the control of tissue growth and development. Genes and Development 12 3162-3167.

Zhong W, Sun T, Wang Y, Xie Y, Johnson A, Leach R, Puscheck EE \& Rappolee DA 2004 SAPK/JNK1, 2, but not SAPK/JNK3 mRNA transcripts, are expressed in early gestation human placenta and mouse eggs, preimplantation embryos, and trophoblast stem cells. Fertility and Sterility. (In Press).

Received 5 April 2004

First decision 25 May 2004

Revised manuscript received 30 June 2004

Accepted 22 July 2004 